Basle Institute for Immunology

\section{A paradise on the Rhine. . .}

THE organizational principle of the Basle Institute for Immunology (BII) can be found on the back of a French coin: Liberté, Egalité, Fraternité. Three Nobel prizes and wide acclaim in the scientific world attest to the wisdom of former director Niels Jerne in setting up the institute the way he did in 1971. Although BII could not exist without the support of Hoffmann-La Roche nor without the hand-picked researchers, it is its organizational structure that sets it apart.

Liberté. Although BII belongs to Hoffmann-La Roche (Roche for short), the researchers are granted "full academic freedom" to publish, teach and collaborate with outside groups of their choice. The support is generous, with an annual budget of SFr24 million for just fifty members, who often use the word "paradise" to describe conditions at BII.

Temporary members (on two- to fiveyear contracts) must first present an idea that the director considers worth exploring. They are paid well and provided with laboratory space and supplies. Then they are expected to produce. Jean-Claude Weill, hired recently as one of the ten permanent members, said the system was "mounted in a shrewd way by Jerne there's no excuse not to work". Another

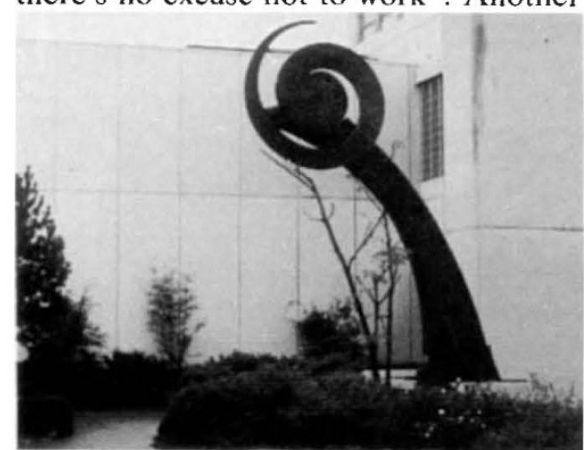

BII boasts this sculpture, "DNA helix" by Jean Tinguely.

member called this realization "the ultimate face- $\grave{a}$-face".

The short contracts can lead to too much orthodoxy, says one member, encouraging temporary members to choose projects that are likely to work rather than taking risks. It is one of the few criticisms to be heard about BII.

Despite the initial pressure, the BII structure allows for individual styles, as well as for projects that take longer than two years. Nobel laureate Susumu Tonegawa, who took the 1987 prize for his work at BH on the generation of antibody diversity, was one of the few to make the transition from temporary to permanent member. (Tonegawa left BII for Massachusetts Institute of Technology in 1981.) Members say that the institute's structure and Jerne's support were pre- requisites for Tonegawa's success.

Egalité Both Jerne and current director Fritz Melchers consider themselves heirs to the spirit of physicist Niels Bohr, who encouraged his students to display a "joyful disregard for authority", says Melchers. "We try to have as little hierarchy as possible" to allow for the most interaction. The high turnover prevents a class system from forming. The only one who stands above the rest is Melchers, who divides his time between his administrative duties and the laboratory.

English is spoken and researchers from all over the world (fewer than 10 per cent are Swiss) use exclusively first names. Outside work time (which spans the entire day and most of the night), the institute plays together too. Not long ago, the staff produced an opera on the immune system in which nearly everyone participated. Even so, original members such as Charles Steinberg (who came to BII from Oak Ridge National Laboratory in Tennessee) say the atmosphere now is more subdued than at the start, "when you would come in the morning and find someone sitting in a tree outside the institute". Fraternité. The 'unit size' of a research group at BII is two people: one member and one technician. This forces collaboration among groups, which can be both a blessing and a curse. According to member Louis Du Pasquier, "The path has twists and turns ... the turnover of people is high and in long-term projects, permanent members cannot always follow their own line as they would with a stable team." Melchers replies: "the institute profits a lot, even if the individual gets a bit frustrated". In terms of productivity, Jerne's grand experiment has been a success. Jerne himself won a Nobel prize in 1984 for his theories concerning the specificity in development and control of the immune system; he is recognized as the spiritual father of modern cellular immunology. He shared the prize with Georges Köhler and César Milstein. Köhler completed his doctoral dissertation at BII in 1974 under Fritz Melchers before going to Milstein's group at the MRC Laboratory of Molecular Biology at Cambridge (UK), where they succeeded in creating the first monoclonal antibodies. BII continues to "develop hidden talents", says Melchers, and turn them loose on the scientific world.

But what's in it for Roche? Former Roche research director Alfred Pletscher cites three goals that Roche owners and management had in mind when BII was conceived in 1968. First came "ethics": Roche was number one in the world in pharmaceuticals and "wanted to give something back" to science. Second, there

\section{Tennis, anyone?}

THERE have been just two directors at BII, Niels Jerne (who left in 1980) and Fritz Melchers. Jerne, a Dane, came to BII from the Paul Ehrlich Institute in West Germany, where he had been frustrated by West German bureaucracy. He created the institute with as little bureaucracy as possible, convinced that this was one key to success in research.

Jerne's management style was one of single-minded intensity. Members compare him to a "golf player"; he pursued a few problems in a linear fashion, such as the generation of antibody diversity, while ignoring others. "He left me with a sense of awe", said Louis Du Pasquier, who has been there since the beginning. "He set a standard so high, it was almost frightening." Says Alfred Pletscher, some people at Roche were "not enthusiastic" about hiring him, calling him "a philosopher". But in retrospect, Jerne's record confirmed that he was the perfect choice.

Melchers, a West German, is more of a "tennis player". A pragmatist who has brought more diversity to the science at BII through his appointments, Melchers relies on continual interaction with members to plot his strategy. More approachable than Jerne, "he lets you do your work and trusts you to do it well", says Du Pasquier. Melchers explains that he wants to keep many lines of inquiry open, despite the fact that most young researchers care only about the genetic approach.

"There are not enough cellular immunologists left; everyone wants to clone a gene. My job is to balance their desire to jump on this bandwagon against long-term interests I think we need to pursue."

S.D.

was the thought that BII could become an important source of talent for the corporate research division of Roche. And finally, there might be patents from which Roche could profit.

In practice, Roche has gained most by hiring BII alumni and using BII as an "open window", as Melchers puts it, onto modern biomedical science. Contact with BII ensures that Roche corporate research does not become "bureaucratized". As a bonus, BII provides the odd patent.

The worst fear among BII members is that someone might turn out the lights in paradise. Melchers acknowledges that the institute's future is dependent on the goodwill of the owners of Roche, who have protected BII before when management had threatened to close it. Melchers admits that there is a chance BII would be disbanded "if we are no longer a centre of excellence in our field". But the lack of a guarantee from Roche also provides an incentive, which, he says, is not all bad. After all, with a permanent lease on paradise, who would work? S.D. 